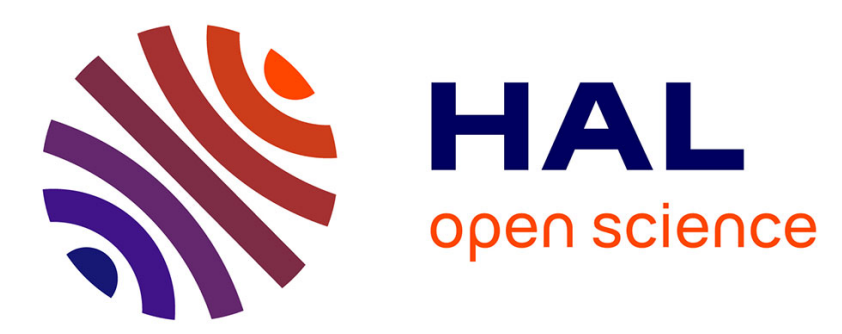

\title{
A two-surface thermomechanical model for saturated clays
}

Peng Yun Hong, Jean-Michel Pereira, Yu-Jun Cui, Anh Minh A.M. Tang

\section{To cite this version:}

Peng Yun Hong, Jean-Michel Pereira, Yu-Jun Cui, Anh Minh A.M. Tang. A two-surface thermomechanical model for saturated clays. International Journal for Numerical and Analytical Methods in Geomechanics, 2016, 40 (7), pp.1059-1080. 10.1002/nag.2474 . hal-01515787

\section{HAL Id: hal-01515787 \\ https://hal-enpc.archives-ouvertes.fr/hal-01515787}

Submitted on 28 Apr 2017

HAL is a multi-disciplinary open access archive for the deposit and dissemination of scientific research documents, whether they are published or not. The documents may come from teaching and research institutions in France or abroad, or from public or private research centers.
L'archive ouverte pluridisciplinaire HAL, est destinée au dépôt et à la diffusion de documents scientifiques de niveau recherche, publiés ou non, émanant des établissements d'enseignement et de recherche français ou étrangers, des laboratoires publics ou privés. 


\title{
A two-surface thermo-mechanical model for saturated clays
}

\author{
P.Y. Hong, J.M. Pereira , Y.J. Cui, A.M. Tang \\ Université Paris-Est, Laboratoire Navier-CERMES, École des Ponts ParisTech, France
}

\begin{abstract}
SUMMARY
This paper presents an advanced thermo-mechanical model - TEAM in the framework of twosurface plasticity for saturated clays, with emphasis put on some important thermomechanical features of natural clays evidenced experimentally such as the limited thermomechanical elastic zone, the smooth transition from elastic to plastic behavior. Two plastic mechanisms are introduced in the model: one is to reproduce the thermo-plasticity involving thermal expansion and contraction observed at high over-consolidation ratios and the second one describes the temperature effect on the yield behavior. The model adopts additional yield surfaces namely Inner yield surfaces that are associated with the two proposed plastic mechanisms to account for the plastic behavior inside the existing conventional thermomechanical yield surface namely Yield surfaces. The general expressions of the yield surfaces and plastic potentials in $p^{\prime}-q-T$ space are introduced. A progressive plastic hardening mechanism associated with the Inner yield surface is defined, enabling the plastic modulus to vary smoothly during thermo-mechanical loadings inside the Yield surfaces. Several tests on natural Boom Clay along different thermo-mechanical loading paths have been simulated by TEAM, and results show its relevance in describing the thermo-mechanical behavior of saturated clays.
\end{abstract}

KEY WORDS: clays; two-surface model; temperature effects; test simulation

\footnotetext{
*Correspondance to: École des Ponts ParisTech, Laboratoire Navier-CERMES, 6-8 av. B. Pascal, 77455 Marnela-Vallée cedex 2, France. Email address: jeanmichel.pereira@enpc.fr 


\section{INTRODUCTION}

The thermo-mechanical behavior of clays has been widely investigated over the past decades for the geomechanical purposes such as nuclear waste geological disposals and energy production (e.g. $[1,2,3,4,5,6,7])$. The main thermo-mechanical features of saturated clays are summarized as follows:

(a) The volume change upon heating is affected by the stress state of over-consolidation ratio (OCR): at low OCR values (close to 1), only thermal contraction occurs; by contrast, at high OCR values, the clay starts with an expansion followed by a contraction.

(b) In the volume-logarithmic mean effective stress plane $\left(v, \ln p^{\prime}\right)$, the slope of the normal compression line is independent of temperature $(T)$.

(c) The pre-consolidation pressure decreases as temperature increases.

(d) The pre-consolidation pressure increases after a heating-cooling cycle on the normally consolidated clays due to the thermal hardening effect.

Based on the experimental evidence, various thermo-mechanical constitutive models for saturated clays were developed. Hueckel and Borsetto [8] proposed the first thermomechanical model within the critical state framework by extending the well-known Modified Cam Clay model (MCC). The temperature effect on the pre-consolidation pressure is taken into account by introducing a yield surface, the size of which being related to temperature. This model can reproduce the plastic strain due to temperature increase in normally consolidated state of soils; however, it cannot well describe the behavior of soils in overconsolidated state. Graham et al. [9] proposed a non-isothermal MCC model in a semigraphical framework rather than the mathematical framework used by Hueckel and Borsetto [8]. However, the thermoplastic behavior in over-consolidated state was still not considered in their model. Robinet et al. [10] developed a thermo-elasto-plastic model by incorporating a microscopic mechanism, in which irreversible thermal strain was considered to control the thermal softening in over-consolidated state of soils. Cui et al. [3] developed a thermomechanical model with a double yield surface in $p^{\prime}-T$ plane: one is the yield limit namely loading yield surface that gives the pre-consolidation pressure as a function of temperature; the second one namely thermal yield surface is introduced to describe the thermal plastic strain in the over-consolidated state. Particular attention was paid to the coupling and hardening phenomena under the combined effects of stress and temperature. Similarly, AbuelNaga et al. [6] developed an isotropic model with two yield limits to capture the volumetric plastic strain induced either by mechanical or by thermal loading based on the results of 
Bangkok clay. Laloui and François [11] developed a thermoplastic model (ACMEG-T) by extending the work of Hujeux [12] based on the multi-surface plasticity theory and this permits to describe the occurrence of plastic strains in the onverover-consolidate state. Yao and Zhou [13] proposed a non-isothermal unified hardening model (UH model) to interpret the thermo-elasto-plastic behavior of normally consolidated and over-consolidated clays, in which a unified hardening parameter $H$ was adopted, with $d H=\frac{M_{f T}{ }^{4}-\eta^{4}}{M_{T}{ }^{4}-\eta^{4}}$ where $M_{f T}$ and $M_{T}$ are the potential failure stress ratio and critical state stress ratio at $T$, respectively, and $\eta$ is the ratio of deviator stress to mean effective stress. With this hardening law, the softening behavior can be modeled. However, it is worth noting that such a hardening law implies that the stress state $\eta=M_{T}$ in the hardening process is a discontinuity point. This will induce difficulties in numerical simulations. The interpretation of the thermo-mechanical behavior of soils at this particular stress state is also difficult. Even though the above mentioned thermomechanical models can capture most thermo-mechanical features observed experimentally, they present limitations or unclear points from the theoretical point of view, as pointed out by Hong et al. [7]. For instance, it is assumed that the hardening parameter conjugated to the preconsolidation pressure increases during a purely elastic process in the model of Abuel-Naga et al. [6], which departs from the classic elasto-plastic theory.

On the other hand, experimental results from isotropic compression tests, drained triaxial shear tests on natural clays such as Boom Clay at different certain temperatures showed complex behavior such as the limited elastic zone (the plastic strain occurs in a early stage before reaching the conventional yield limit) and the smooth transition from elastic to plastic state (progressive stiffness degradation with strain) $([2,14])$. These features should be taken into account in thermo-mechanical models. Recently, Hong [15] has developed a two surface model (ACC-2) for describing these important features of natural clay behavior under isothermal condition. The model uses new general expressions for the yield surface and plastic potential with the MCC yield surface as a special case. A new plastic mechanism similar to that in the bounding surface concept, namely two-surface plasticity, is proposed allowing the smooth evolution of hardening modulus in the over-consolidated state.

In this study, a two-surface thermo-mechanical model called TEAM is developed in the framework of elasto-plasticity theory and based on the model proposed by Cui et al. [3] and ACC-2. The thermo-elasto-plastic behavior in both isotropic and triaxial stress state is described by the model. First, the volume change induced by mechanical stress and 
temperature thermo-mechanical yielding behavior for the isotropic states are described defined. Emphasis is put on the link between the volumetric plastic strains along mechanical and thermal loading paths. Then, the thermo-mechanical model is presented, with the new yield surfaces, the hardening law and the flow rule developed in non-isothermal conditions. Finally, the model is validated by simulating experimental tests along different thermomechanical paths.

\section{THERMO-MECHANICAL YIELDING BEHAVIOR FOR ISOTROPIC STATES}

The purpose of this section is to present the forms of the conventional thermal-mechanical yield curves as well as the corresponding hardening laws in the mean effective stresstemperature space $\left(p^{\prime}, T\right)$ based on observed features of isotropic thermo-mechanical tests. The equations mainly follow the thermo-mechanical model proposed by Cui et al. [3] (referred to as Model C).

\subsection{Thermo-mechanical yield limits}

Within the framework of elasto-plastic theory, a thermo-mechanical elastic zone that indicates the first occurrence of plastic strain should be defined. Following Model C, an elastic zone delimited by two yield curves is adopted (see Figure 1): the yield curve denoted LY (loading yield limit) is controlled by the evolution of pre-consolidation pressure $\bar{p}_{c 0}^{\prime}$ at a reference temperature $T_{0}$, and the plastic volumetric strain in normally consolidated state is related to the evolution of LY; the yield curve denoted TY (thermal yield limit) is used to govern the thermal plastic behavior inside LY. Note that the definition and expression of TY are modified in respect to Model C, as shown below.

The same expression for LY as that used in Model C is adopted:

$$
\bar{p}_{c T}^{\prime}=\bar{p}_{c 0}^{\prime} \exp \left[-\alpha_{0}\left(T-T_{0}\right)\right]
$$

where $\bar{p}_{c 0}^{\prime}$ and $\bar{p}_{c T}^{\prime}$ are defined as the apparent pre-consolidation pressures at an initiat reference temperature $T_{0}$ and the actual temperature $T$, respectively, $\alpha_{0}$ is a parameter governing the curvature of LY. 


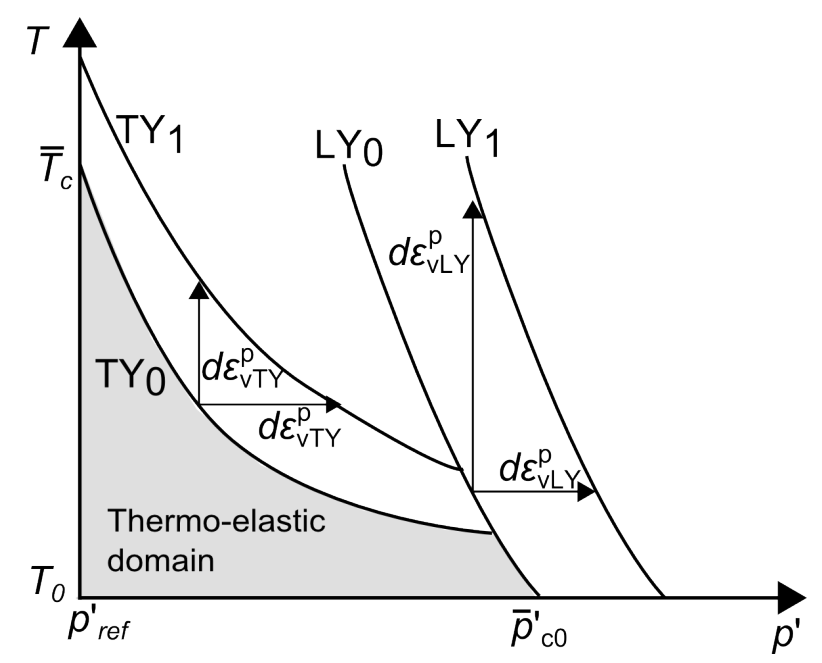

Figure 1. Plastic strain increments generated during thermal and /or mechanical loadings.

As presented by Sultan et al. [4, 16] As shown in Figure 2(a), heating over-consolidated clay leads to a thermal volumetric expansion followed by a contraction (see Figure 2(a)). The higher the OCR values the higher the temperature of transition from expansion to contraction. It has been shown that the thermal expansion corresponds to a thermal elastic behavior while the thermal contraction corresponds to a thermo-plastic behavior. Thereby, a transition point can be defined namely thermal yield point (or yield temperature). Following the approach of Wood [17] for the yield stress determination, the yield temperature is similarly determined as the intersection point (points $\mathrm{Y} 1, \mathrm{Y} 2$ and $\mathrm{Y} 3$ ) of the two linear parts of the $\varepsilon_{v}^{T}$-T curve (see Figure 2(a)). The loci of these transition points define the TY curve.

In view of this definition, the thermal expansion and contraction observed at high overconsolidation ratios can be described by the TY curve. A function providing a shape similar (see Figure 2(b)) to that used in Model C is defined, as follows:

$$
T_{T Y}=\bar{T}_{c}-\frac{1}{\beta} \ln \left(\frac{p^{\prime}}{p_{\text {ref }}^{\prime}}\right)
$$

where $p_{r e f}^{\prime}$ is a reference pressure taken equal to the atmospheric pressure $(0.1 \mathrm{MPa}), T_{\mathrm{TY}}$ and $\bar{T}_{c}$ are the yield temperature values corresponding to $p^{\prime}$ and $p_{r e f}^{\prime}$, respectively, $\beta$ is a parameter controlling the shape of TY curve. 


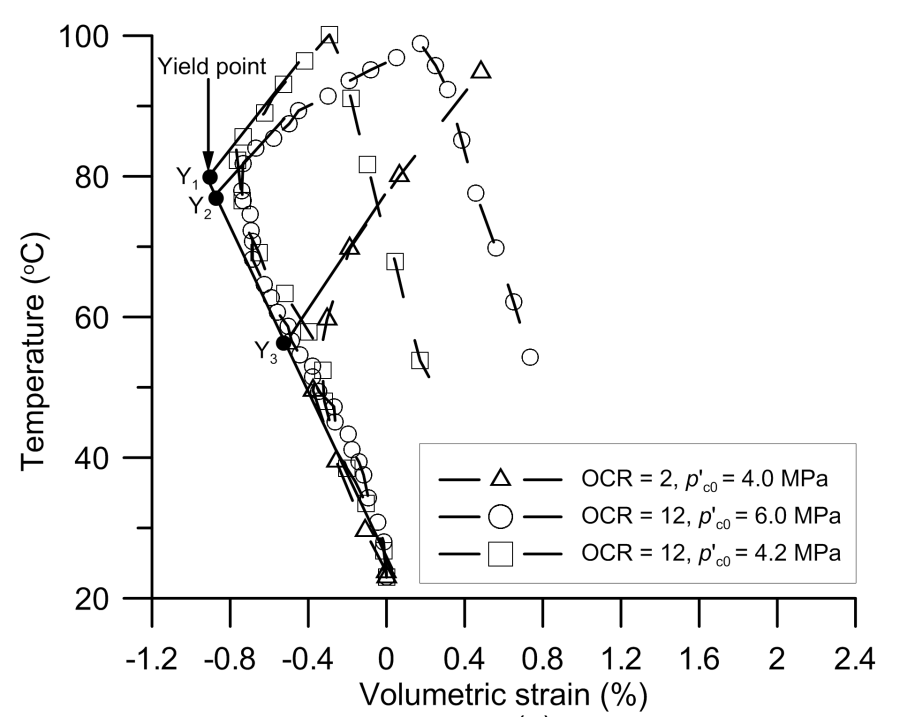

(a)

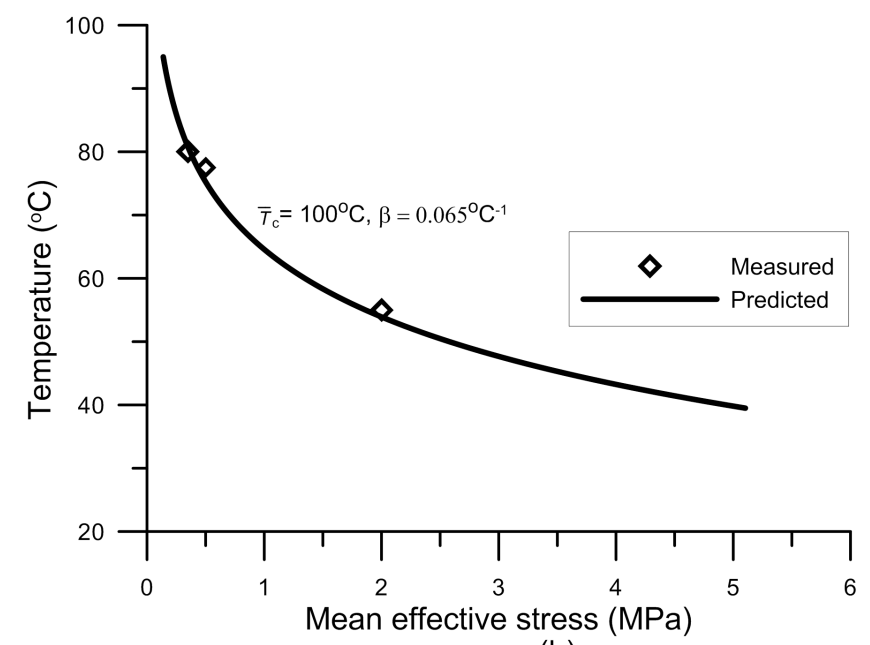

(b)

Figure 2. Determination of the yield temperature for remolded Boom Clay $[4,16]$ under different isotropic stresses (a), and comparison between the experimental yield points and the proposed thermal yield curve TY (b).

\subsection{Thermo-mechanical hardening laws}

Thermo-plastic volumetric strain occurs upon heating in normally consolidated state, i.e. $d \varepsilon_{v L Y}^{p}$ induced by thermal loading on LY locus. This plastic mechanism corresponds to a decrease of pre-consolidation pressure with the increase of temperature, known as thermal softening. The thermo-plastic volumetric strain is generated during a heating process at constant mean stress, compensating the thermal softening: the loading point is maintained on the loading yield curve (LY). In other words, the thermo-plastic volumetric strain on LY curve is generated along heating paths because of the reduction of pre-consolidation pressure with the increase of temperature. Thereby, the plastic strains along a mechanical loading path and a thermal loading path are theoretically linked. For the purpose of illustration, consider a 
series of isotropic tests in which the soil samples at a reference temperature $T_{0}$ (point 1 in Figure 3) are subjected to two different thermo-mechanical loading paths, denoted path A (13-1'-2) and path B (1-2), respectively. Along path A, the soil is heated from 1 to 3 and behaves thermo-elasto-plastically. Purely thermo-elastic strain occurs in the cooling process from 3 to $1^{\prime}$. Due to the thermal hardening effect, $L Y$ evolves from $\mathrm{LY}_{0}$ to $\mathrm{LY}_{1}$ and an elastic mechanical behavior is expected during the following mechanical loading from 1'-2. Along path $\mathrm{B}$, a normal compression behavior is expected with a slope $\lambda$ in the $\left(v, \ln p^{\prime}\right)$ plane. The plastic volume change that occurs along path A must be equal to that along path $\mathrm{B}$, independently of the loading path, and can thus be expressed as:

$$
\Delta v^{p}=v_{1}-v_{1^{\prime}}=(\lambda-\kappa) \ln \frac{p_{2}^{\prime}}{p_{1}^{\prime}}
$$

Therefore, the plastic volumetric strain $\left(d \varepsilon_{v L Y}^{p}\right)$ induced by different loading paths between $\mathrm{LY}_{0}$ and $\mathrm{LY}_{1}$ can be calculated from the change in size of LY:

$$
d \bar{p}_{c 0}^{\prime}=\frac{v_{0}}{(\lambda-\kappa)} \bar{p}_{c 0}^{\prime} d \varepsilon_{v L Y}^{p}
$$

It should be pointed out that a single plastic strain variable associated with LY is defined irrespective of loading paths in the hardening law, whereas, the plastic strain variables along a mechanical loading path and a thermal loading path are distinct and defined respectively on LY in Model C [7] . 


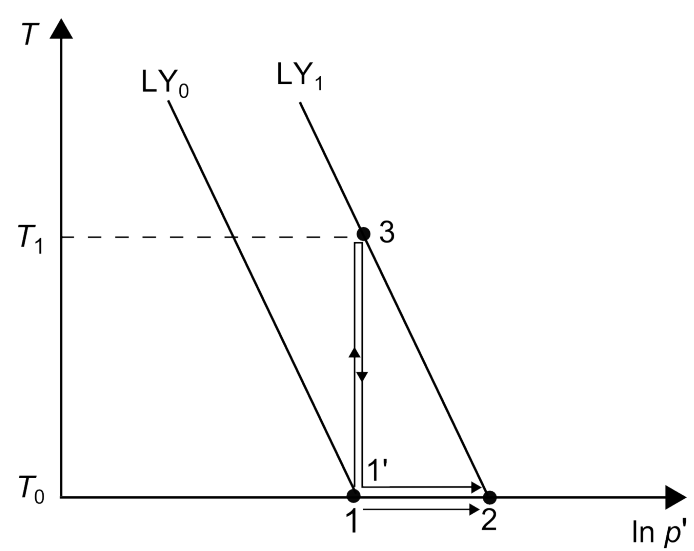

(a)

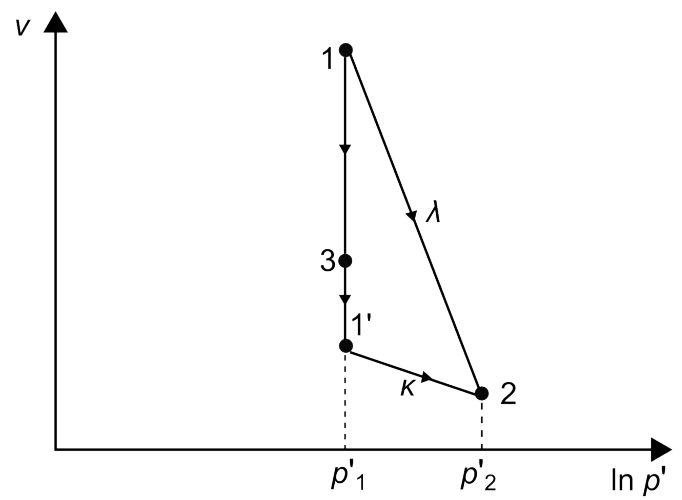

(b)

Figure 3. Shape of LY in $\left(p^{\prime}, T\right)$ plane and thermo-mechanical loading paths (a), and volumetric response to the thermo-mechanical loading for a normally consolidated clay in the $\left(v, \ln p^{\prime}\right)$ space $(b)$.

Using Equations (1) and (4), the plastic volumetric strain increment associated with LY (OCR always being equal to 1 ) induced by the temperature change can be expressed in such a form, as follows:

$$
d \varepsilon_{v L Y}^{p}=\frac{(\lambda-\kappa) \alpha_{0}}{v_{0}} d T
$$

This is consistent with the findings shown by Demars and Charles [18]: the plastic strain induced by temperature on normally consolidated soils only depends on an increase in temperature, with no influence from the applied stress. Thus, in the special case at the intersection point between TY and LY with $\mathrm{OCR}=1$, the thermally induced plastic volumetric strain on TY $\left(d \varepsilon_{v T Y}^{p}\right)$ can also be calculated from Equation (5). However, in an over-consolidated state, experimental results show that the thermally induced plastic strain depends on the stress state (OCR effect). $d \varepsilon_{v T Y}^{p}$ on TY in the stress state with any OCR values $(\mathrm{OCR} \geq 1)$ can be determined by:

$$
d \varepsilon_{v T Y}^{p}=\frac{(\lambda-\kappa) \alpha_{0}}{v_{0} f(O C R)} d T
$$


where OCR $=p_{c T}^{\prime} / p^{\prime}$ corresponds to the distance from the current stress state to the yield locus LY at a given temperature. $f(\mathrm{OCR})$ is a function describing the OCR effect. This function should satisfy the following conditions:

$$
\begin{aligned}
& f(1)=1 \\
& \lim _{O C R \rightarrow+\infty} f=+\infty
\end{aligned}
$$

This implies that when no effective stress is applied, i.e. OCR $\rightarrow+\infty$, the thermal behavior is purely elastic, and when TY and LY intersect, the thermally induced volumetric strains associated with TY and LY are identical. The function $f(\mathrm{OCR})$ will be determined later, in framework of two-surface plasticity.

Irrespective of loading path, $d \varepsilon_{v T Y}^{p}$ can be determined by the hardening law associated with TY:

$$
d \bar{T}_{c}=\frac{v_{0}}{(\lambda-\kappa) \alpha_{0}} f(O C R) d \varepsilon_{v T Y}^{p}
$$

\section{MODEL DESCRIPTION IN TRIAXIAL CONDITIONS}

\subsection{Main features relative to the thermo-mechanical behavior in the triaixal stress space}

In the triaixal space, the constitutive modeling tools (yield surfaces and plastic potentials) have to be formulated in $\left(p^{\prime}, q, T\right)$ space. The equations of the yield curves defined in $\left(p^{\prime}, T\right)$ plane can be extended to $\left(p^{\prime}, q, T\right)$ space by incorporating the deviator stress parameter $q$ and including the shear stress effect. In order to define the plastic potentials or flow rule, it is necessary to specify the shear strength at an elevated temperature.

Heating may induce strength changes due to an alteration of the physical properties such as adsorption forces in clay water ([19]). However, existing experimental data (Boom clay, Spanish clay, Pontida clay, Kaolin clay) $[5,15,20,21]$ does not give clear general trends of temperature effects on the slope of the critical state line (CSL) in $\left(p^{\prime}, q\right)$ plane, $M_{\mathrm{g}}$. This slope has been observed to increase, or remain constant or even decrease with temperature increase. For instance, $M_{\mathrm{g}}$ was found to be temperature independent for Pontida clay by Hueckel and Pellegrini [20] but to slightly decrease with temperature for Spanish clay by Hueckel et al. [21]. Hueckel et al. [22] concluded that the dependence of shear strength on temperature may be material specific. In addition, it should also be pointed out that the differences of $M_{\mathrm{g}}$ values may be induced by the sample inhomogeneity ([2, 23]), specimen preparation process such as an inappropriate resaturation process which may alter the thermo-hydro-mechanical 
behavior $([14,24])$, the thermo-mechanical loading history, and the drainage conditions under which the heating is performed.

In this study, the temperature effects on the slope $M_{\mathrm{g}}$ for natural Boom Clay are examined in depth based on experimental results $[2,14,25]$. To eliminate the effects related to the thermomechanical loading history, the variability in experimental techniques such as drainage conditions or more specifically the sample resaturation process, only drained triaxial experimental tests on samples saturated under the in situ stress are considered. All the samples are taken at a depth of $223 \mathrm{~m}$ from the underground research facility at $\mathrm{Mol}$ in Belgium. The shear strength at critical state obtained from tests at $25^{\circ} \mathrm{C}$ and $76^{\circ} \mathrm{C}$ are plotted in Figure 4.

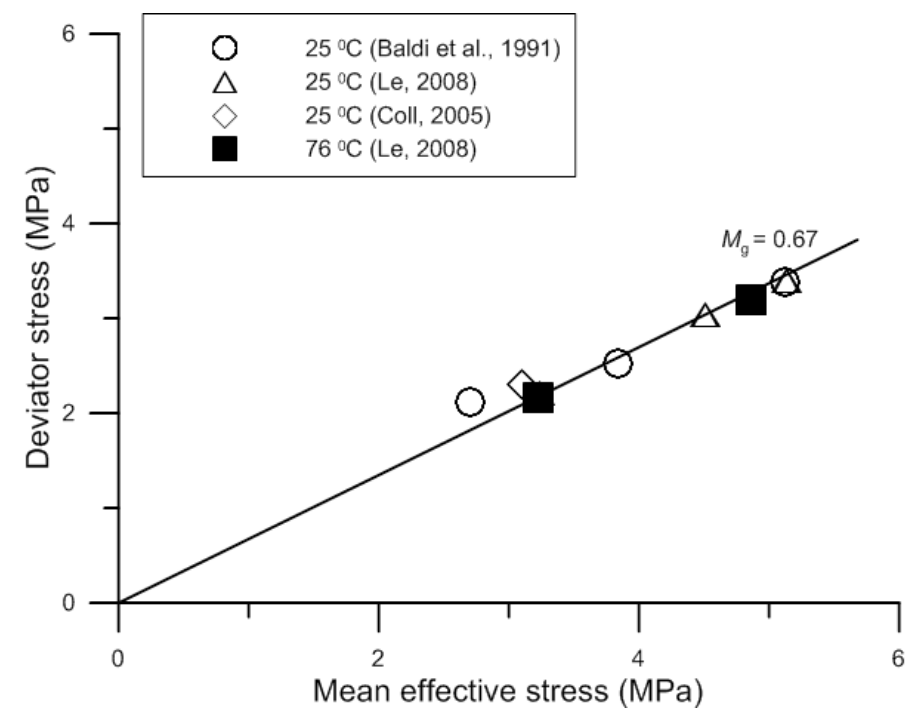

Figure 4. Critical state line of natural Boom Clay at two different temperatures.

It seems that the shear strength of natural Boom Clay is not influenced by temperature. Following Model $\mathrm{C}$, it is therefore assumed that $M_{\mathrm{g}}$ is temperature independent, which is also supported by Cekerevac and Laloui [5] from a summary of some experimental results in literature.

\subsection{Elastic behavior}

The total elastic volumetric increment $d \varepsilon_{v}^{e}$ is defined by Equation Erreur ! Source du renvoi introuvable. . associated with mechanical and thermal loadings can be calculated using the equation proposed by Model C:

$$
d \varepsilon_{v}^{e}=\frac{d p^{\prime}}{K}-\alpha_{d} d T
$$

with bulk modulus $K$ defined as in MCC model:

$$
K=\frac{v_{0} p^{\prime}}{\kappa}
$$


where $\kappa$ is the temperature independent elastic slope in $\left(v, \ln p^{\prime}\right)$ plane, $v_{0}$ is the initial specific volume, $\alpha_{d}$ is the drained thermal volumetric expansion coefficient which is assumed to be constant. As pointed out by Hong et al. [7], taking a constant value of $\alpha_{d}$ permits to remain simple in describing the thermo-elastic behavior, and at the same time to ensure that the elastic behavior is loading path independent.

The elastic shear strain is assumed to be temperature independent purely mechanical (that is not influenced by temperature changes), thus:

$$
d \varepsilon_{s}^{e}=\frac{d q}{3 G}
$$

The shear modulus $G$ is obtained by assuming a constant Poisson's ratio $v$ :

$$
G=\frac{3(1-2 v)}{2(1+v)} K
$$

Even though this choice (Eq. (12)) is commonly used for simulating experimental results, it should be pointed out that it is thermodynamically inconsistent since the Maxwell symmetry relations are not satisfied in this case $[26,27]$.

\subsection{Yield surfaces}

The basic thermo-mechanical model (i.e. Model C) was developed based on MCC, which satisfactorily describes the main features of clay behavior but is not capable of well describing the observed shear behavior of clay such as the smooth transition from elastic to plastic state. This is because Model $\mathrm{C}$ is based on a simple elasto-plastic framework, which is consistent with the determination of conventional yield points by considering the sharp slope change in the stress-strain plot.

To capture a smooth transition from the elastic state to the elastoplastic state, a two-surface approach is applied. In this study, the yield surfaces shown in Figure 5 are introduced: the conventional yield surfaces comprising LY and TY namely Yield surfaces represent the conventional yield behavior; the Inner yield surfaces comprising ILY and ITY describe the yielding behavior inside the Yield surfaces. The hardening variables $T_{\mathrm{c}}$ and $\bar{T}_{c}$ with respect to ITY and TY respectively, $p_{\mathrm{c} 0}^{\prime}$ and $\bar{p}_{c 0}^{\prime}$ with respect to ILY and LY respectively are introduced. Note that $\bar{p}_{c 0}^{\prime}$ and $\bar{T}_{c}$ correspond to the conventional hardening variables, as introduced in Model C. The variables $T_{\mathrm{c}}$ and $p_{\mathrm{c} 0}^{\prime}$ are analogous to $\bar{T}_{c}$ and $\bar{p}_{c 0}^{\prime}$ respectively, as illustrated in Figure 5. 
Two scalars giving the ratios of the size of Yield surface to that of the corresponding Inner yield surface are introduced for each mechanism. Their values are always smaller than or equal to 1. For LY plastic mechanism, this ratio is denoted $r_{L Y}$ and reads:

$$
r_{L Y}=\frac{p_{c 0}^{\prime}}{\bar{p}_{c 0}^{\prime}}
$$

For natural clays, the initial size of ILY is defined by the initial in-situ effective stress at the initial temperature, thus neglecting any elastic nucleus. It is worth noting that the initial value of $r_{L Y}$ corresponds thus to the inverse of OCR, as commonly defined.

Similarly, for TY plastic mechanism, $r_{T Y}$ is defined by:

$$
r_{T Y}=\frac{T_{c}}{\bar{T}_{c}}
$$
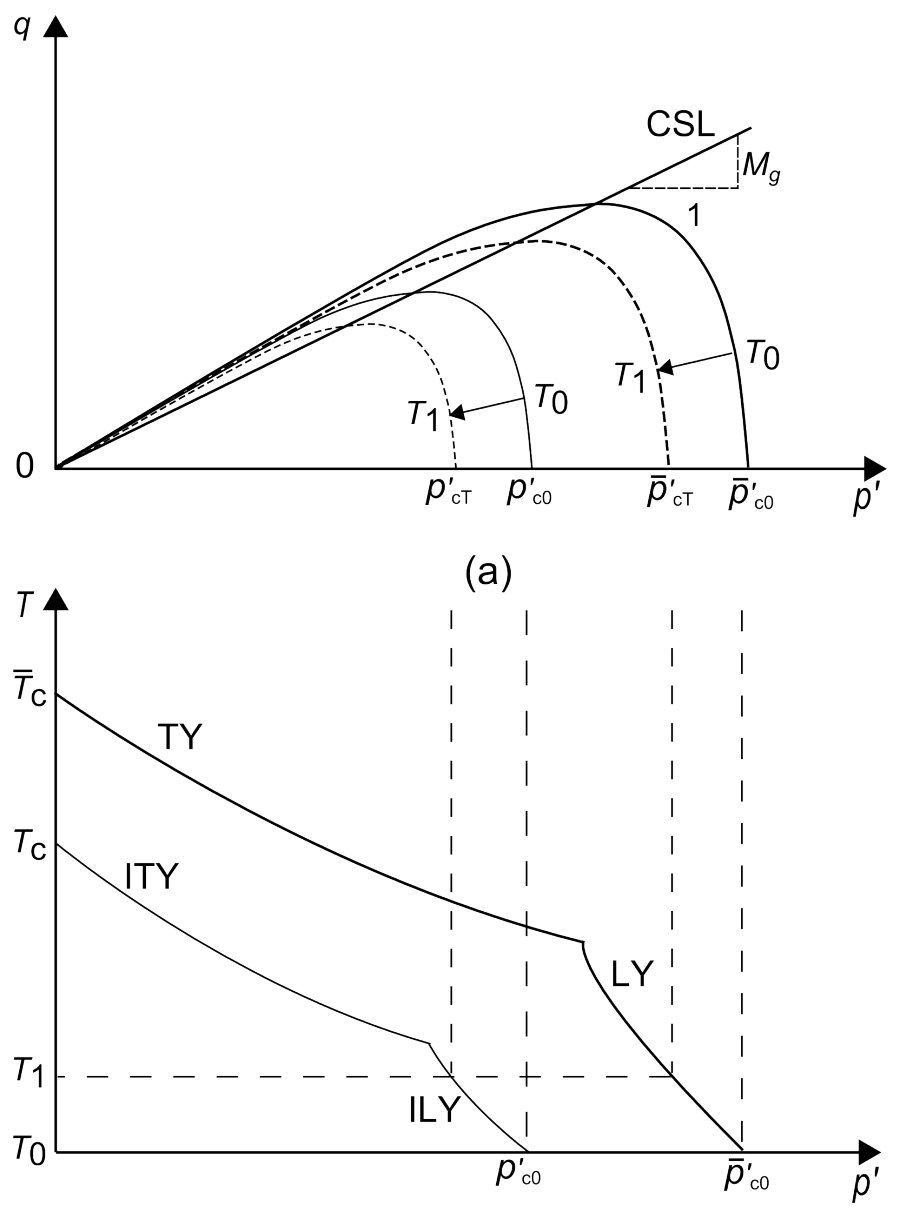

(b)

Figure 5. Yield locus in $\left(p^{\prime}-q\right)$ plane at two different temperatures (with $\left.T_{1}>T_{0}\right)(\mathrm{a})$, and in $\left(p^{\prime}-T\right)$ plane (b). 
At a given temperature (T), a generalized yield surface proposed by McDowell and Hau [28] is used for LY to achieve a wide variety of yield surface shapes in $p^{\prime}-q$ plane. The yield surface LY in $p^{\prime}-T$ plane (i.e. Eq. (1)) is adopted to consider the temperature effect. Thereby, the expression of LY in $p^{\prime}-q-T$ space is given as follows:

$$
f_{L Y} \equiv q^{2}+\frac{M_{f}^{2}}{1-k_{f}}\left(\frac{p^{\prime}}{\bar{p}_{c T}^{\prime}}\right)^{2 / k_{f}} \bar{p}_{c T}^{\prime 2}-\frac{M_{f}^{2} p^{\prime 2}}{1-k_{f}}=0
$$

With

$$
\bar{p}_{c T}^{\prime}=\bar{p}_{c 0}^{\prime} \exp \left[-\alpha_{0}\left(T-T_{0}\right)\right]
$$

where $M_{f}$ defines the stress ratio at the apex of the yield surface, $k_{f}$ is a parameter used to specify the shape of the yield surface. For the sake of brevity but without losing generality, it is assumed that $k_{f}$ is not equal to 1 . The case of $k_{f}=1$ is discussed in the Appendix I. Figure 6 presents the curve predicted by the LY function at two different temperatures with the parameters in Table II for natural Boom Clay, as determined from drained triaxial shear tests $[2,14,25]$. The corresponding critical state line is also drawn with $M_{\mathrm{g}}$ being equal to $M_{\mathrm{f}}$ and the critical state line passes through the apex of the yield surface as shown in the figure. However, the intersection point between the critical state line and the yield surface would not occur at the apex of the yield surface (as opposed to MCC) if $M_{\mathrm{f}} \neq M_{\mathrm{g}}$.

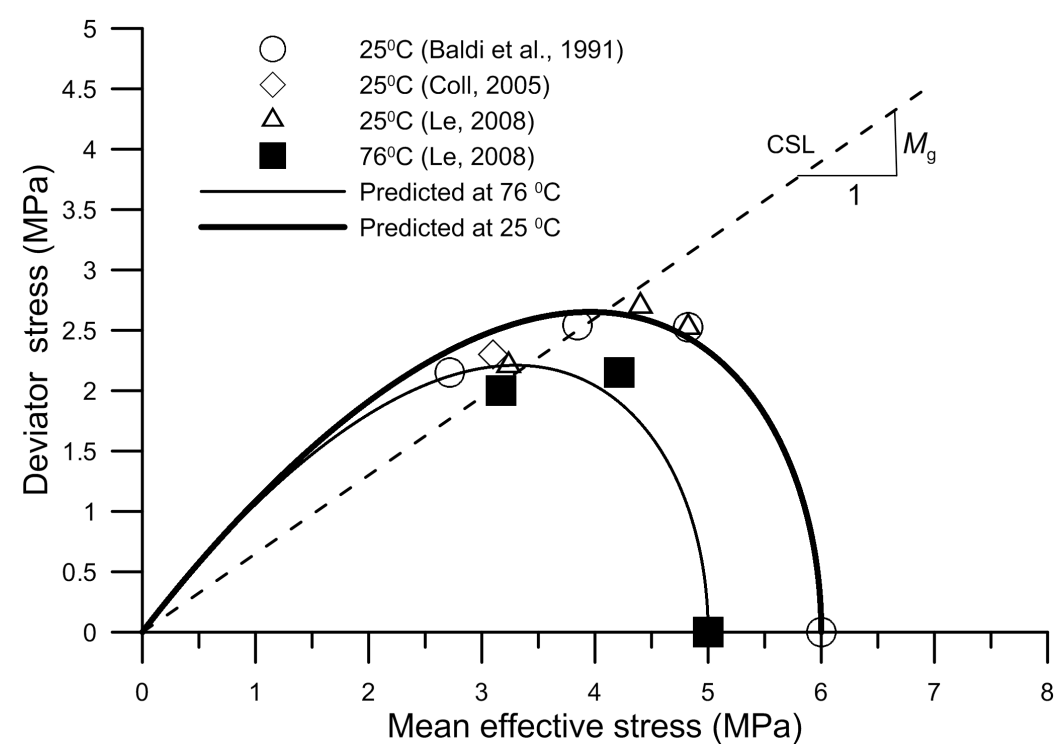

Figure 5 6. Predicted yield curve of LY for natural Boom Clay at $25^{\circ} \mathrm{C}$ and $76^{\circ} \mathrm{C}$.

Since ILY is homologous to LY with respect to the origin in $p^{\prime}-q-T$ space, based on Equations (13) and (15), the function of ILY is given by:

$$
f_{I L Y} \equiv q^{2}+\frac{M_{f}^{2}}{1-k_{f}}\left(\frac{p^{\prime}}{r_{L Y} \bar{p}_{c T}^{\prime}}\right)^{2 / k_{f}}\left(r_{L Y} \bar{p}_{c T}^{\prime}\right)^{2}-\frac{M_{f}^{2} p^{\prime 2}}{1-k_{f}}=0
$$


Similarly, the expressions of TY and ITY are defined as follows:

$$
\begin{gathered}
f_{T Y} \equiv T-\bar{T}_{c}+\frac{1}{\beta} \ln \left(\frac{p^{\prime}}{p_{r e f}^{\prime}}\right)=0 \\
f_{I T Y} \equiv T-r_{T Y} \bar{T}_{c}+\frac{1}{\beta} \ln \left(\frac{p^{\prime}}{p_{r e f}^{\prime}}\right)=0
\end{gathered}
$$

\subsection{Hardening law}

The hardening parameters $\bar{p}_{c 0}^{\prime}$ and $r_{L Y}$ are defined to control the size of LY and ILY, respectively. As shown in Equation (4), the internal variable increment of $d \bar{p}_{c 0}^{\prime}$ depends on the volumetric plastic strain increment $\left(d \varepsilon_{v L Y}^{p}\right)$ associated with LY plastic mechanism. Furthermore, the experimental observations in Cui et al. [3] showing that hardening of LY occurs when TY is activated while activation of LY does not produce any hardening of TY, a unidirectional coupling between TY and LY is considered as in Model C. Therefore, the plastic strain increment associated with TY plastic mechanism will also induce an increase of $\bar{p}_{c 0}^{\prime}$ and the evolution law of $\bar{p}_{c 0}^{\prime}$ can be defined as follows:

$$
d \bar{p}_{c 0}^{\prime}=\frac{v_{0}}{\lambda-\kappa} \bar{p}_{c 0}^{\prime}\left(d \varepsilon_{v T Y}^{p}+d \varepsilon_{v L Y}^{p}\right)
$$

To describe the hardening modulus variation upon thermo-mechanical loading as ITY is activated, the evolution law of $r_{L Y}$ can be written as:

$$
d r_{L Y}=\frac{v_{0}}{\lambda-\kappa} S_{L Y}\left(1-r_{L Y}\right)\left(d \varepsilon_{v T Y}^{p}+d \varepsilon_{v L Y}^{p}+A_{d} d \varepsilon_{s L Y}^{p}\right)
$$

where $s_{L Y}$ is a material constant which controls the rate of ILY approaching LY along the thermo-mechanical loading paths and thus describes the degradation of the slope of stress/temperature-strain curve inside LY. It actually intervenes in the evolution rate of $r_{L Y} . A_{d}$ is a parameter that controls the contribution of shear plastic strain $d \varepsilon_{s L Y}^{p}$ to the soil hardening. With such a combined volumetric-deviatoric hardening law, the inclusion of shear hardening part leads to plastic hardening modulus $h>0$ (see Equations (38) and (33)) even when the effective stress along with the inner loading yield surface reaches the CSL, and then hardening/softening continues with the effective stress increase over the CSL. This allows the description of the softening behavior. Accounting for the contribution of $r_{L Y}$ (i.e. Eq. (21)), the overall hardening modulus decreases as $r_{L Y}$ increases from an initial value of $r_{L Y 0}$ to 1 , which 
enables a smooth elastic-plastic transition. If $r_{L Y}=1$, ILY and LY coincide and both surfaces evolve at the same rate since $d r_{L Y}=0$ according to Equation(21). It is as if ILY is cancelled.

The hardening laws for TY and ITY are respectively defined as:

$$
\begin{gathered}
d \bar{T}_{c}=\frac{v_{0}}{(\lambda-\kappa) \alpha_{0}} f(O C R) d \varepsilon_{v T Y}^{p} \\
d r_{T Y}=\frac{v_{0}}{(\lambda-\kappa) \alpha_{0} \bar{T}_{c}} f(O C R) s_{T Y}\left(1-r_{T Y}\right) d \varepsilon_{v T Y}^{p}
\end{gathered}
$$

with the function $f(\mathrm{OCR})$ satisfying Equation (7) and now reading:

$$
f(O C R)=1+s_{L Y}\left(1 / r_{L Y}-1\right)
$$

where $s_{T Y}$ is a material constant that controls the rate of ITY approaching TY along thermomechanical loading paths and thus describes the degradation of the slope of stress/temperature-strain curve inside TY. It actually intervenes in the evolution rate of $r_{T Y}$. Similarly, with the contribution of $r_{T Y}$, a smooth elasto-plastic transition can be predicted as ITY is activated. Note that with the above hardening laws, the Inner Yield surfaces (ITY and ILY) of the proposed model can be simply switched off if $r_{T Y}=1$ and $r_{L Y}=1$, which makes the proposed model and Model C similar.

\subsection{Plastic potentials}

The expressions of the plastic potentials corresponding to ILY and LY takes the same form as the yield surfaces, as follows:

$$
\begin{gathered}
g_{I L Y} \equiv q^{2}+\frac{M_{g}^{2}}{1-k_{g}}\left(\frac{p^{\prime}}{r_{L Y} \delta_{T}}\right)^{2 / k g}\left(r_{L Y} \delta_{T}\right)^{2}-\frac{M_{g}^{2} p^{\prime 2}}{1-k_{g}}=0 \\
g_{L Y} \equiv q^{2}+\frac{M_{g}^{2}}{1-k_{g}}\left(\frac{p^{\prime}}{\delta_{T}}\right)^{2 / k g}\left(\delta_{T}\right)^{2}-\frac{M_{g}^{2} p^{\prime 2}}{1-k_{g}}=0
\end{gathered}
$$

This leads to a non-associated flow rule if $M_{\mathrm{g}} \neq M_{\mathrm{f}}$ or $k_{\mathrm{g}} \neq k_{\mathrm{f}}$. In the case of triaxial compression, the dilation ratio is given by:

$$
d=\frac{d \varepsilon_{v L Y}^{p}}{d \varepsilon_{s L Y}^{p}}=\frac{M_{g}{ }^{2}-\eta^{2}}{k_{g} \eta}
$$

where $\eta$ is the stress ratio $q / p^{\prime} ; k_{\mathrm{g}}$ is a parameter used to specify the ratio between the plastic volumetric strain increment and the plastic shear strain increment, $k_{\mathrm{g}}=2$ leading to the flow rule of MCC model; $\delta_{T}$ is a size parameter and can be determined by solving Equation (25) at a given stress state $\left(p^{\prime}, q\right)$ as done by $\mathrm{Yu}$ [29]. To consider the temperature effects on the shear strength and plastic strain increment ratio, the flow rule can be easily extended by 
adopting functions of temperature for $M_{\mathrm{g}}(T)$ and $k_{\mathrm{g}}(\mathrm{T})$. As shown previously, $M_{\mathrm{g}}$ and $k_{\mathrm{g}}$ are assumed to be temperature independent on the basis of the experimental observations on natural Boom Clay.

For ITY or TY, the volumetric plastic strain is given by Equations (22) and (23) and the shear plastic strain increment is assumed to be null.

\subsection{Consistency equations}

The constitutive equations of the proposed TEAM model can be described in a way similar to that of conventional elastoplastic models. The plastic strain rate is formulated by applying the consistency condition on the Inner yield surfaces (ITY or ILY or both) and presented in a general manner.

The total strain increment $(d \boldsymbol{\varepsilon})$ can be split into three parts: an elastic strain increment $d \boldsymbol{\varepsilon}_{\boldsymbol{\sigma}^{\prime}}^{e}$ associated with the effective stress changes, a stress independent thermal elastic increment $d \boldsymbol{\varepsilon}_{T}^{e}$ due to temperature changes and a plastic increment $d \boldsymbol{\varepsilon}^{p}$ due to the effective stress and temperature changes:

$$
d \boldsymbol{\varepsilon}=d \boldsymbol{\varepsilon}_{\sigma^{\prime}}^{e}+d \boldsymbol{\varepsilon}_{T}^{e}+d \boldsymbol{\varepsilon}^{p}
$$

The elastic strain $d \boldsymbol{\varepsilon}_{\boldsymbol{\sigma}^{\prime}}^{e}$ and $d \boldsymbol{\varepsilon}_{T}^{e}$ is are defined respectively, as:

$$
\begin{gathered}
d \boldsymbol{\varepsilon}_{\sigma^{\prime}}^{e}=\mathbf{D}_{e}^{-1} d \boldsymbol{\sigma}^{\prime} \\
d \boldsymbol{\varepsilon}_{T}^{e}=-\frac{1}{3} \mathbf{m} \alpha_{d} d T
\end{gathered}
$$

where $\mathbf{D}_{e}$ is the elastic matrix, $\mathbf{m}$ is the column vector with 1 at normal stress entries and 0 at shear stress entries.

In the proposed model, two different cases may be encountered during a plastic loading process depending on the stress - temperature state: the loading state is on one yield surface or at the intersection points between ITY and ILY. Considering first the former case, the plastic strain increment is computed from the plastic potential:

$$
d \boldsymbol{\varepsilon}_{I}^{p}=d \lambda_{I} \frac{\partial g_{I}}{\partial \boldsymbol{\sigma}^{\prime}}
$$

where $d \lambda_{\mathrm{I}}$ is the plastic multiplier, a positive scalar, and $g_{I}$ is the plastic potential corresponding to the activated plastic mechanism, subscript I standing for the considered Inner yield surface (ILY or ITY).

$\mathbf{X}_{I}$ denotes a vector of hardening variables:

$$
\mathbf{X}_{I}=\left\{X_{I 1}, X_{I 2}\right\}^{t}
$$


where $X_{I 1}=\bar{T}_{c}$ and $X_{I 2}=r_{I Y}$ if $\left(\sigma^{\prime}, T\right)$ is on ITY, $X_{I 1}=\bar{p}_{c 0}^{\prime}$ and $X_{I 2}=r_{L Y}$ if $\left(\sigma^{\prime}, T\right)$ is on ILY, respectively.

The hardening law can thus be written in a general form as follows:

$$
d \mathbf{X}_{I}=d \lambda \mathbf{B}
$$

where $\mathbf{B}=\left\{B_{1}, B_{2}\right\}^{t}, \quad B_{1}=\frac{\partial r_{T Y}}{\partial \varepsilon_{v T Y}^{p}} \frac{\partial g_{I T Y}}{\partial p^{\prime}} \quad$ and $\quad B_{2}=\frac{\partial \bar{T}_{c}}{\partial \varepsilon_{v T Y}^{p}} \frac{\partial g_{I T Y}}{\partial p^{\prime}} \quad$ if ITY is activated; $B_{1}=\frac{\partial \bar{p}_{c 0}^{\prime}}{\partial \varepsilon_{v L Y}^{p}} \frac{\partial g_{I L Y}}{\partial p^{\prime}}+\frac{\partial \bar{p}_{c 0}^{\prime}}{\partial \varepsilon_{v T Y}^{p}} \frac{\partial g_{I T Y}}{\partial p^{\prime}}$ and $B_{2}=\frac{\partial r_{L Y}}{\partial \varepsilon_{v T Y}^{p}} \frac{\partial g_{I T Y}}{\partial p^{\prime}}+\frac{\partial r_{L Y}}{\partial \varepsilon_{v L Y}^{p}} \frac{\partial g_{I L Y}}{\partial p^{\prime}}+\frac{\partial r_{L Y}}{\partial \varepsilon_{s L Y}^{p}} \frac{\partial g_{I L Y}}{\partial q}$ if ILY is activated. Their detailed formulations are given in Equations (20)-(24).

The consistency condition can be expressed as:

$$
d f_{I}=\left(\frac{\partial f_{I}}{\partial \boldsymbol{\sigma}^{\prime}}\right)^{t}: d \boldsymbol{\sigma}^{\prime}+\frac{\partial f_{I}}{\partial T} d T+\left(\frac{\partial f_{I}}{\partial \mathbf{X}_{I}}\right)^{t}: d \mathbf{X}_{I}=0
$$

where $f_{\mathrm{I}}$ is the activated yield surface.

The stress increment can be expressed as:

$$
d \boldsymbol{\sigma}^{\prime}=\mathbf{D}_{e} d \boldsymbol{\varepsilon}_{\boldsymbol{\sigma}^{\prime}}^{e}=\mathbf{D}_{e}\left(d \boldsymbol{\varepsilon}+\frac{1}{3} \mathbf{m} \alpha_{d} d T-d \boldsymbol{\varepsilon}_{I}^{p}\right)
$$

where the elastic strain $d \boldsymbol{\varepsilon}_{\sigma^{\prime}}^{e}$ is calculated from Equations (28) and (30).

By substituting Equations (31), (33) and (35) into (34), the differential stress-strain equations can be obtained if ILY or ITY is activated:

$$
d \boldsymbol{\sigma}^{\prime}=\mathbf{D}_{e p}^{\varepsilon} d \boldsymbol{\varepsilon}+\mathbf{D}_{e p}^{T} d T
$$

where:

$$
\begin{gathered}
\mathbf{D}_{e p}^{\varepsilon}=\mathbf{D}_{e}-\frac{\mathbf{D}_{e} \mathbf{g}_{I}\left(\mathbf{a}_{I}\right)^{t} \mathbf{D}_{e}}{\left(\mathbf{a}_{I}\right)^{t} \mathbf{D}_{e} \mathbf{g}_{I}+h} \\
\mathbf{D}_{e p}^{T}=\frac{\mathbf{D}_{e} \mathbf{g}_{I}\left[\left(\mathbf{a}_{I}\right)^{t} \mathbf{D}_{e} \mathbf{b}-\mathbf{c}_{I}\right]}{\left(\mathbf{a}_{I}\right)^{t} \mathbf{D}_{e} \mathbf{g}_{I}+h}-\mathbf{D}_{e} \mathbf{b}
\end{gathered}
$$

$\mathbf{a}_{I}=\frac{\partial f_{I}}{\partial \boldsymbol{\sigma}^{\prime}}, \mathbf{b}=-\frac{1}{3} \mathbf{m} \alpha_{d}, \mathbf{c}_{I}=\frac{\partial f_{I}}{\partial T}, \mathbf{g}_{I}=\frac{\partial g_{I}}{\partial \boldsymbol{\sigma}^{\prime}}, h=-\left(\frac{\partial f_{I}}{\partial \mathbf{X}_{I}}\right)^{t} \frac{\partial \mathbf{X}_{I}}{\partial \mathbf{B}}$.

If the stress-temperature state is at the intersection point of the two Inner yield surfaces (ITY and ILY), i.e. $f_{\mathrm{ITY}}=0$ and $f_{\mathrm{ILY}}=0$, both consistency conditions must be satisfied, that is: 


$$
\left\{\begin{array}{l}
d f_{I T Y}=\left(\frac{\partial f_{I T Y}}{\partial \boldsymbol{\sigma}^{\prime}}\right)^{t}: d \boldsymbol{\sigma}^{\prime}+\frac{\partial f_{I T Y}}{\partial T} d T+\left(\frac{\partial f_{I T Y}}{\partial \mathbf{X}_{I T Y}}\right)^{t}: d \mathbf{X}_{I T Y}=0 \\
d f_{I L Y}=\left(\frac{\partial f_{I L Y}}{\partial \boldsymbol{\sigma}^{\prime}}\right)^{t}: d \boldsymbol{\sigma}^{\prime}+\frac{\partial f_{I L Y}}{\partial T} d T+\left(\frac{\partial f_{I L Y}}{\partial \mathbf{X}_{I L Y}}\right)^{t}: d \mathbf{X}_{I L Y}=0
\end{array}\right.
$$

The total plastic strain increment is the sum of the plastic strains due to each mechanism (ITY and ILY):

$$
\begin{gathered}
d \boldsymbol{\varepsilon}^{p}=d \boldsymbol{\varepsilon}_{I T Y}^{p}+d \boldsymbol{\varepsilon}_{I L Y}^{p} \\
=d \lambda_{I T Y} \mathbf{g}_{I T Y}+d \lambda_{I L Y} \mathbf{g}_{I L Y}
\end{gathered}
$$

and the stress increment can be expressed as:

$$
d \boldsymbol{\sigma}^{\prime}=\mathbf{D}_{e}\left(d \boldsymbol{\varepsilon}+\frac{1}{3} \mathbf{m} \alpha_{d} d T-\overline{\mathbf{g}} d \lambda\right)
$$

where $\overline{\mathbf{g}}=\left(g_{I T Y}, g_{I L Y}\right), d \lambda=\left\{d \lambda_{I T Y}, d \lambda_{I L Y}\right\}^{t}$.

Equations (39) and (41) provide the values of the two plastic multipliers, $d \lambda_{I T Y}$ and $d \lambda_{I L Y}$. When both values are positive, the two mechanisms are activated simultaneously. However, it is possible that one of them is negative. This means that the corresponding mechanism is not activated and the plastic multiplier has to be set to zero.

The proposed TEAM model can be easily well implemented numerically using the integration algorithms presented in Hong et al. [30] for a thermo-mechanical model with specific technical points such as the treatment of the intersection between two plastic mechanisms, for instance.

\section{DETERMINATION OF PARAMETERS}

The proposed TEAM model has 17 parameters $\left(\lambda, \kappa, v, \bar{p}_{c 00}^{\prime}, \alpha_{\mathrm{d}}, \alpha_{0}, r_{L Y 0}, s_{L Y}, \beta, \bar{T}_{c 0}, r_{T Y 0}\right.$, $\left.s_{T Y}, M_{\mathrm{f}}, k_{f}, M_{\mathrm{g}}, k_{\mathrm{g}}, A_{\mathrm{d}}\right)$. The procedure for their determination is described below:

1) $\lambda, \kappa, v, \bar{p}_{c 00}^{\prime}, M_{\mathrm{g}}$ are common parameters of MCC and can be determined in a similar fashion. $\lambda$ and $\kappa$ are the slopes of normal consolidation compression line and swelling line of the isotropic compression curve in $\left(v, \ln p^{\prime}\right)$ plane, respectively. $\bar{p}_{c 00}^{\prime}$ denotes the initial value of $\bar{p}_{c 0}^{\prime}$, i.e. the initial conventional isotropic pre-consolidation pressure at a reference temperature $T_{0}$, which defines the initial size of LY curve. These three parameters $(\lambda, \kappa$ and $\bar{p}_{c 00}^{\prime}$ ) can be determined from a loading-unloading isotropic compression test at any given temperature since they are temperature independent. The Poisson's ratio $v$ can be determined from a triaxial test by considering the elastic behavior (at a low strain around $0.5 \%$ ) in the $\varepsilon_{\mathrm{V}^{-}}$ 
$\varepsilon_{1}$ plane: $v=\left(1-\varepsilon_{v} / \varepsilon_{1}\right) / 2 . M_{\mathrm{g}}$ is the critical state stress ratio and can be determined by the effective stress ratio at the critical state along different thermo-mechanical loading paths.

2) The drained thermal volumetric expansion coefficient of soil $\alpha_{d}$ can be calibrated from the cooling stage of a drained heating-cooling test.

3) The $p^{\prime}-T$ yield locus LY is defined by parameter $a_{0}$ (see Eq. (16)). This parameter can be determined from at least 2 isotropic compression tests on overconsolidated specimens at two different temperatures.

4) The initial ITY is defined through the initial yield temperature $\bar{T}_{c 0}$ and the shape parameter $\beta$ by Equation (18). At least two heating tests at different overconsolidation ratios are required to deduce the thermal yield point on the $\varepsilon_{v}^{T}-T$ curves (see Figure 2 (a)). The values of $\bar{T}_{c 0}$ and $\beta$ are then obtained from Equation (18) by best fitting the yield values in $\left(p^{\prime}-T\right)$ plane.

5) $r_{L Y 0}$ specifies the size of ILY associated with the first occurrence of plastic strains. For natural clay, the initial size of the Inner yield surface is defined by the initial in-situ effective stress. In this regard, $r_{L Y 0}$ at the initial temperature corresponds to the inverse of OCR, as commonly defined. Similarly, $r_{T Y 0}$ specifies the initial size of ITY. With the initial stresstemperature state on ITY, $r_{T Y 0}$ is then obtained from Equation (19).

6) Parameter $s_{L Y}$ influences the hardening rate of ILY and thus describes the slope of the stress/temperature-curve inside LY. This parameter can thus be calibrated from the stressstrain curve of an isotropic mechanical loading test at a given temperature. $s_{T Y}$ defines the hardening rate of ITY and can be calibrated from the $\varepsilon_{v}^{T}-T$ plot of isotropic heating test on an overconsolidated specimen.

7) $M_{\mathrm{f}}$ and $k_{\mathrm{f}}$ are parameters affecting the shape of LY in $\left(p^{\prime}, q\right)$ plane at a given temperature. These two parameters can be calibrated by fitting the LY shape to the conventional yield points in different radial directions in $\left(p^{\prime}, q\right)$ plane (see Figure 5).

8) $k_{\mathrm{g}}$ is used to describe the plastic flow rule and can be determined by the values of $d \varepsilon_{v}^{p} / d \varepsilon_{s}^{p}$ obtained from drained triaxial shear tests at a given temperature $T$.

9) $A_{\mathrm{d}}$ describes the contribution of the shear plastic strain in the hardening process. It can be back-calibrated by fitting the experimental results from triaxial shear tests, especially the ones showing the softening behavior.

\section{PREDICTION AND VALIDATION}


In this section, the performance of TEAM model is evaluated by predicting the thermomechanical behavior of reconstituted Pontida Clay [19] and natural Boom Clay [2, 14]. The capability of the proposed model to predict the isotropic and shear thermo-mechanical behavior is examined.

\subsection{Tests on reconstituted Pontida Clay}

The heating and cooling tests in isotropic stress states on reconstituted Pontida Clay with different OCRs are considered.

\subsubsection{Heating-cooling tests in isotropic stress state}

Baldi et al. [19] performed three heating tests on reconstituted Pontida Clay. As shown in Figure 7, three specimens were first loaded up to $p^{\prime}=2.5 \mathrm{MPa}$ (path O-A in Figure 7). Afterwards, two specimens were unloaded to $1 \mathrm{MPa}$ (path A-B) and $0.2 \mathrm{MPa}$ (path A-D), respectively. Thus, three specimens with three different over-consolidation ratios $(1,2.5$, and 12.5) were obtained. From these consolidation pressures, a heating process was applied on each specimen. The results of the tests are presented in Figure 8. Due to the previous mechanical loadings on the samples prior to heating, $r_{\mathrm{LY}}=1$ holds and LY and ILY are identical for the heating process simulation. In the simulation, Parameters $\lambda$ and $\kappa$ are taken from the results of Hueckel and Pellegrini [31] from an isotropic compression test at $21^{\circ} \mathrm{C}$. With a pre-consolidation pressure decreased from $2.5 \mathrm{MPa}$ at $21^{\circ} \mathrm{C}$ to $1.90 \mathrm{MPa}$ at $90^{\circ} \mathrm{C}$ [31], parameter $\alpha_{0}$ is obtained. The other parameters are determined based on the experimental results from the heating tests on over-consolidated samples (OCR $=2$ and 12.5): $\beta, \bar{T}_{c 0}, r_{T Y 0}$ are derived from their yield points and $\alpha_{\mathrm{d}}, s_{T Y}$ are determined by curve fitting to obtain the best simulation of the experimental curve with $\mathrm{OCR}=2$ in $\varepsilon_{v}^{T}-T$ plane. As mentioned above, the thermally induced strain in the normal consolidation state can be calculated from the size change of LY $\left(d \bar{p}_{c 0}^{\prime}\right)$. The heating test with OCR $=1$ is thus excluded from the parameter determination process and the simulation a blind one. The initial state of reconstituted Pontida Clay is normally consolidated with $e_{0}=0.88$, and under $p^{\prime}=0.1 \mathrm{MPa}$, $T_{0}=20^{\circ} \mathrm{C}$. The adopted parameters are presented in Table I.

Table I. Model parameters for reconstituted Pontida Clay 


\begin{tabular}{cccccc}
\hline$\lambda$ & $\kappa$ & $\bar{p}_{c 00}^{\prime}(\mathrm{MPa})$ & $\alpha_{\mathrm{d}}\left(1 /{ }^{\circ} \mathrm{C}\right)$ & $\alpha_{0}\left(1 /{ }^{\circ} \mathrm{C}\right)$ & $r_{L Y 0}$ \\
\hline 0.103 & 0.016 & 0.1 & 0.00005 & 0.0035 & 1.0 \\
\hline$S_{L Y}$ & $\beta$ & $\bar{T}_{c 0}$ & $r_{T Y 0}$ & $S_{T Y}$ & \\
\hline $10^{*}$ & 0.072 & 110 & 0.18 & 12 & \\
\hline
\end{tabular}

*the parameter has no effect since $r_{L Y 0}=1$

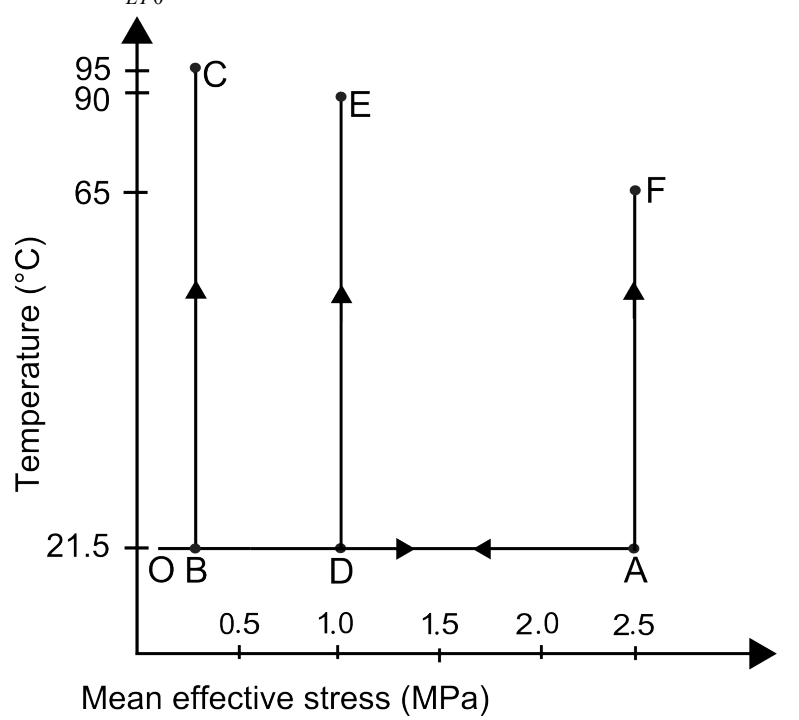

Figure 7. Isotropic thermo-mechanical loading paths on Pontida Clay

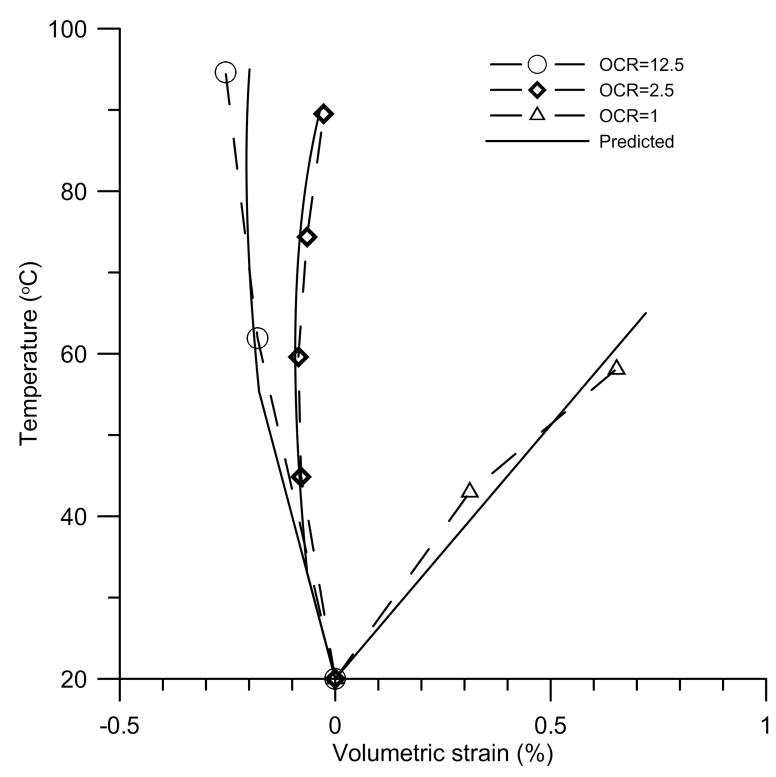

Figure 8. Comparison between predicted and measured results of the heating tests on reconstituted Pontida Clay at different OCR values.

The comparison between the experimental and predicted thermally induced volume changes in different over-consolidated states are given in Figure 8. It is worth noting that in the heating 
test at $\mathrm{OCR}=1$, the thermally induced volume change is-linked to the plastic mechanism of LY as $r_{L Y}=1$ holds, showing that plastic volumetric strains occurring during the thermal loading and mechanical loading are similar in nature. The corresponding numerical predictions in over-consolidated state where the volume changes are controlled by the thermal yield plastic mechanisms of ITY and TY, are also in good agreement with the experimental results. Note also that thanks to the introduced two-surface mechanism, there is a smooth transition when the plastic mechanism associated with the ITY curve is activated.

\subsection{Tests on natural Boom Clay}

The Boom Clay samples considered were taken at $\mathrm{Mol}$ at a depth of $223 \mathrm{~m}$. The initial state is defined by $e_{0}=0.61, p^{\prime}=2 \mathrm{MPa}, T_{0}=21.5^{\circ} \mathrm{C}$. It is worth noting that saturating the samples of Boom Clay under low effective stress states induces significant swell ([24, 32]) and the subsequent thermo-mechanical tests may not be representative of the behavior of natural Boom Clay. Therefore, only data obtained from the tests on samples saturated under the in situ effective stress (around $2 \mathrm{MPa}$ ) are considered in this study.

A set of tests on natural Boom Clay performed by Baldi et al. [2] and Le [14] is taken into account, including the heating and cooling tests under isotropic stress states with different OCRs, isotropic compression tests and drained triaxial test at different temperatures. The model parameters are presented in Table II. Parameters $\lambda, \kappa, r_{L Y 0}, \bar{p}_{c 00}^{\prime}$ and $s_{L Y}$ are determined by best fitting of from an isotropic compression curve in $v$-ln $p^{\prime}$ plane at the reference temperature $21.5^{\circ} \mathrm{C}$ (TBoom 1 in Figure 12); Parameters $M_{\mathrm{f}}, k_{\mathrm{f}}$ governing the yield surface shape in triaxial space are derived based on from the yield points of two drained triaxial shear tests at $25^{\circ} \mathrm{C}\left(\mathrm{CD}-1\right.$ and CD-2 in Figures 13 and 14); $k_{\mathrm{g}}, A_{\mathrm{d}}, v$ are calibrated by best fitting to the $\varepsilon_{\mathrm{v}}-\varepsilon_{1}$ curve of CD-1 and $M_{\mathrm{g}}$ are determined with the critical stress ratio in CD-1; Parameter $\alpha_{0}$ is obtained from the isotropic compression tests at two different temperatures (TBoom1 and TBoom11 in Figure 12), by considering the preconsolidation pressure $6 \mathrm{MPa}$ at

$21.5^{\circ} \mathrm{C}$ and $4.2 \mathrm{MPa}$ at $95^{\circ} \mathrm{C}$ previously determined; Parameters $\beta, r_{T Y 0}, \bar{T}_{c 0}, s_{T Y}$ and $\alpha_{d}$ are determined from the- $\varepsilon v-T$ plot of a heating tests on an over-consolidated sample (paths $p^{\prime}=$ $1 \mathrm{MPa}$ and $p^{\prime}=3 \mathrm{MPa}$ of Tboom9 in Figure 10): $\beta, \bar{T}_{c 0}, r_{T Y 0}$ are derived from their yield points and $\alpha_{\mathrm{d}}, s_{T Y}$ are determined by fitting the experimental curve in $\varepsilon_{v}^{T}-T$ plane with $p^{\prime}=$ $3 \mathrm{MPa}$. The other tests, including the heating-cooling test at $p^{\prime}=6 \mathrm{MPa}$ of Tboom9, isotropic compression test at $65^{\circ} \mathrm{C}$ of Tboom 10 , two drained triaxial tests at $76^{\circ} \mathrm{C}$ of TCD-1 and TCD-2 are excluded from the parameter determination process and the simulations are blind. 
Table II. Model parameters for natural Boom Clay

\begin{tabular}{ccccccccc}
\hline$\lambda 1$ & $\mathrm{k} \kappa$ & vn & $\bar{p}_{c 00}^{\prime}(\mathrm{MPa})$ & $\alpha_{\mathrm{d}}\left(1 /{ }^{\circ} \mathrm{C}\right)$ & $\alpha_{0}\left(1 /{ }^{\circ} \mathrm{C}\right)$ & $r_{L Y 0}$ & $s_{L Y}$ & $\beta$ \\
\hline 0.18 & 0.02 & 0.3 & 6 & 0.00005 & 0.005 & 0.33 & 8 & 0.021 \\
\hline & & & & & & & & \\
\hline $\bar{T}_{c 0}$ & $r_{T Y 0}$ & $S_{T Y}$ & $M_{\mathrm{f}}$ & $k_{\mathrm{f}}$ & $M_{\mathrm{g}}$ & $k_{\mathrm{g}}$ & $A_{\mathrm{d}}$ \\
\hline 216 & 0.76 & 1.2 & 0.67 & 0.7 & 0.67 & 0.9 & 0.1 \\
\hline
\end{tabular}

\subsubsection{Heating-cooling tests in isotropic stress states}

The thermo-mechanical test on natural Boom Clay (TBoom9) reported by Baldi et al. [2] is considered. The thermo-mechanical loading path followed in the test (see Figure 9) can be summarized as follows: the specimen was first saturated under a constant mean effective stress of $2 \mathrm{MPa}$ and then isotropically loaded up to $4 \mathrm{MPa}$ (path A-B in Figure 9) and unloaded to $1 \mathrm{MPa}$ (path B-C) prior to heating; The first heating-cooling cycle of $21.5^{\circ} \mathrm{C}-$ $95^{\circ} \mathrm{C}-21.5^{\circ} \mathrm{C}$ (path C-D-E) was applied under a constant mean effective stress of $1 \mathrm{MPa}$; a subsequent mechanical isotropic reloading up to $3 \mathrm{MPa}$ (path E-F) was applied and followed by a second heating-cooling cycle under $3 \mathrm{MPa}$ (path F-G-H); finally, a mechanical isotropic reloading up to $6 \mathrm{MPa}$ (path $\mathrm{H}-\mathrm{I}$ ) was applied and followed by a third heating-cooling cycle under $6 \mathrm{MPa}$ (path I-J-K). Following the loading path, the volumetric strain is set to 0 at the starting of each heating-cooling stage in the calculation. It is observed that the numerical simulations fit well with the experimental results for the thermal path at $p^{\prime}=6 \mathrm{MPa}$, while a slight difference exists for the two other paths as shown in Figure 10. On the whole, the thermal expansion and contraction at different OCRs are satisfactorily described by the proposed model. 


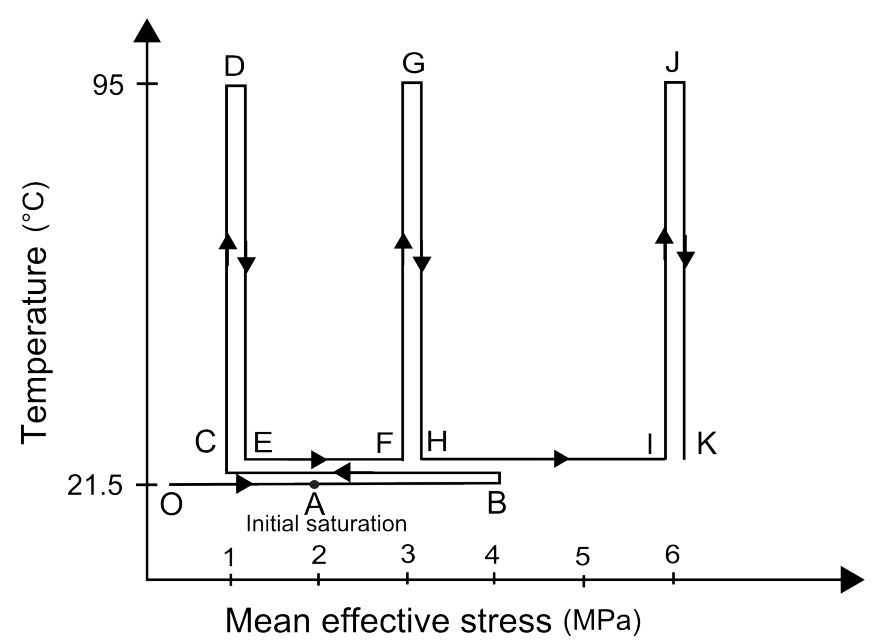

Figure 9. Isotropic thermo-mechanical loading path followed during TBoom9 test on natural Boom Clay [7]

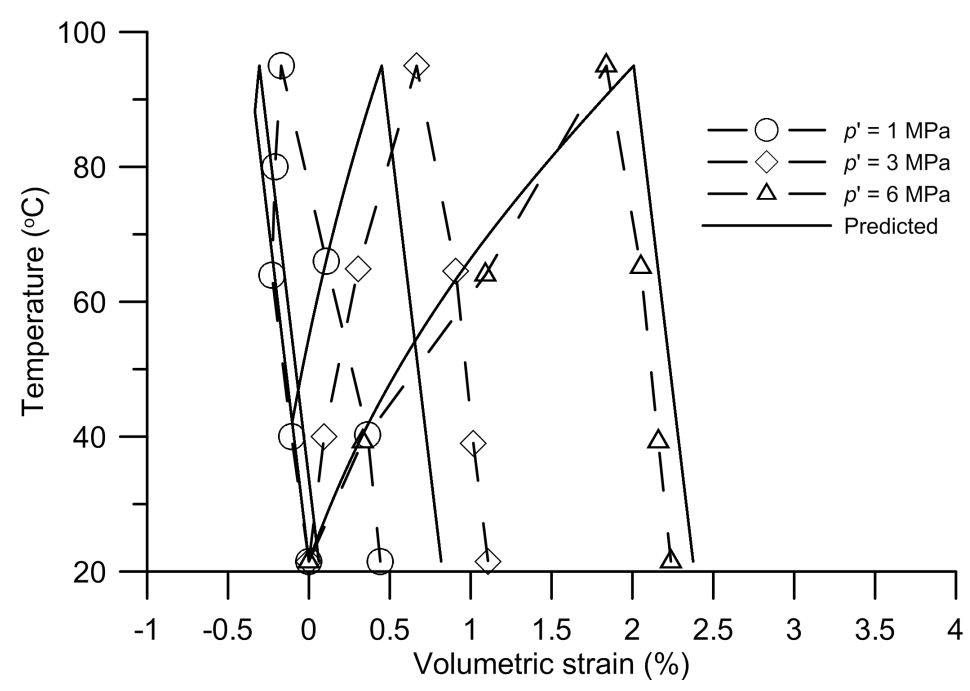

Figure 10. Comparison between the experimental results and model predictions from heating-cooling tests at different stresses on natural Boom Clay.

\subsubsection{Isotropic compression tests at different temperatures}

The isotropic compression tests at different temperatures (TBoom1, TBoom10 and TBoom11) performed by Baldi et al. [2] are considered. The experimental loading paths are depicted in Figure 11. After completion of the saturation process under a mean effective stress of $2 \mathrm{MPa}$, different thermo-mechanical loading paths were applied: in Tboom1, isotropic loading up to 8 $\mathrm{MPa}$ and then unloading to $1 \mathrm{MPa}$ at $21.5^{\circ} \mathrm{C}$; in TBoom 10 and TBoom11, unloading from the initial stress of $2 \mathrm{MPa}$ to $1 \mathrm{MPa}$, respectively heating from $21.5^{\circ} \mathrm{C}$ to $65^{\circ} \mathrm{C}$ and $95^{\circ} \mathrm{C}$, respectively loading at $65^{\circ} \mathrm{C}$ and $95^{\circ} \mathrm{C}$ up to $8 \mathrm{MPa}$ and then unloading to $1.0 \mathrm{MPa}$.

The predictions of tests TBoom1, TBoom10 and TBoom11 at three different temperatures are shown in Figure 12. A general trend involving volumetric strain is observed from the experimental curves: at a given stress level, the higher the temperature the larger the 
volumetric strain. The proposed model can capture this feature with the elastic zone that shrinks with the pre-consolidation pressure decrease due to temperature increase. Moreover, the smooth elasto-plastic behavior during the mechanical compression at different temperatures can be well described by the model.

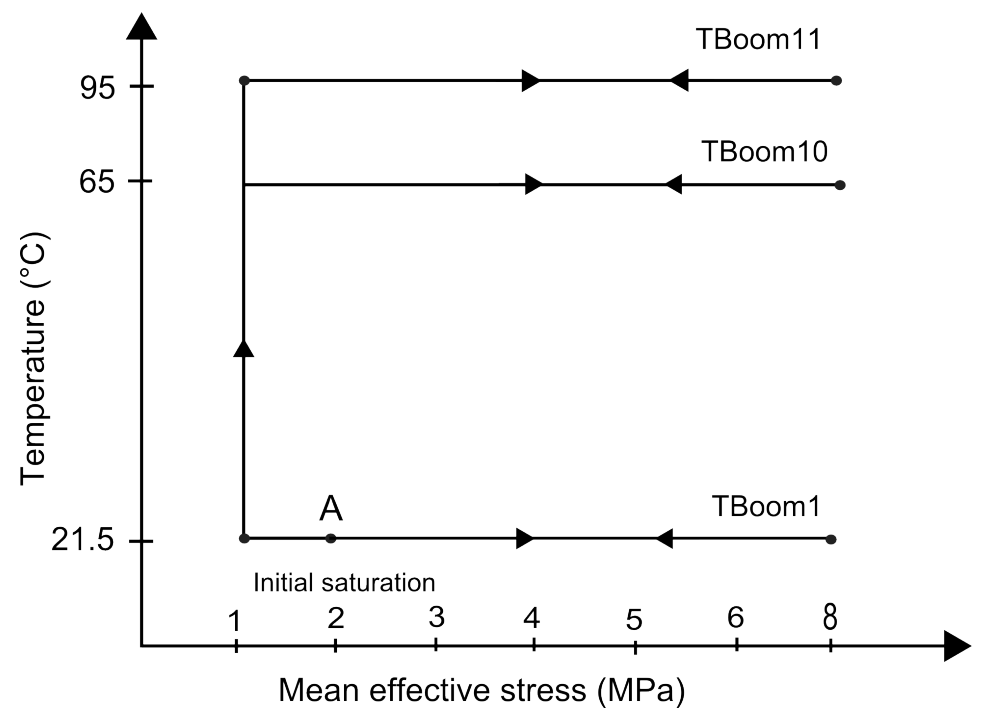

Figure 11. Test programs for TBoom1, TBoom10 and TBoom11 tests.

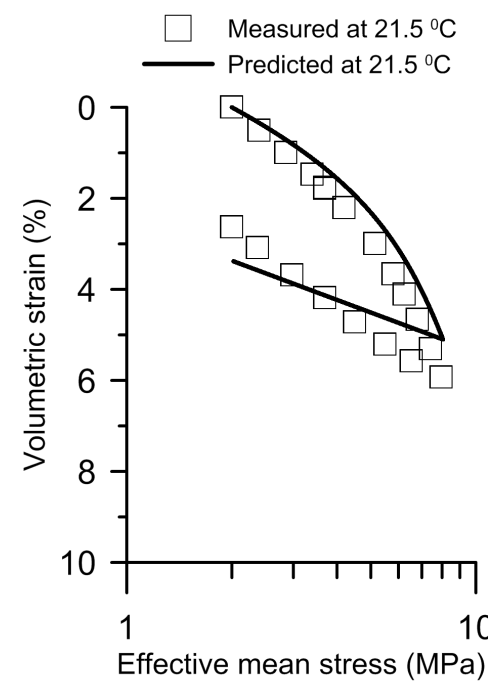

(a)

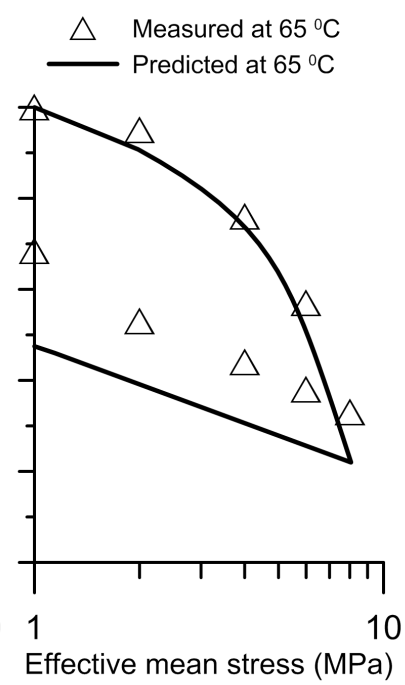

(b)

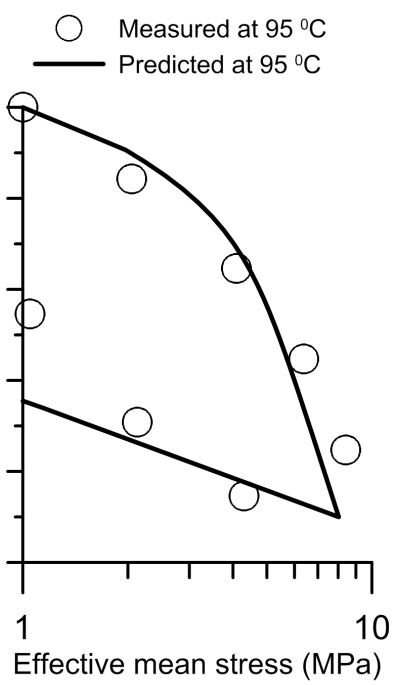

(c)

Figure 12. Simulations of the isotropic compression tests on natural Boom Clay at different temperatures.

\subsubsection{Triaxial shear test}

Two drained triaxial shear tests $(\mathrm{CD}-1$ and $\mathrm{CD}-2)$ at ambient temperature $\left(25^{\circ} \mathrm{C}\right)$ and two drained triaxial shear tests (TCD-1 and TCD-2) at an elevated temperature $\left(71.6^{\circ} \mathrm{C}\right)$ are considered. Note that test CD-2 was performed by Baldi et al. [2] while the other tests were performed by Le [14]. After the saturation process under the in-situ effective stress, an isotropic loading path was applied followed by a triaxial shearing path. In CD-1, the sample 
was loaded from an isotropic mean effective stress of $2.5 \mathrm{MPa}$ and then sheared under a constant confining pressure at $25^{\circ} \mathrm{C}$. In $\mathrm{CD}-2$, an isotropic loading to $4 \mathrm{MPa}$ was performed under drained conditions at $25^{\circ} \mathrm{C}$. At $4 \mathrm{MPa}$, triaxial shearing was carried out under two unloading-reloading cycles at $0.6 \%$ and $3.8 \%$ axial strain, respectively. In TCD-1, after the saturation process under an initial mean effective stress of $2.5 \mathrm{MPa}$, the sample was isotropically consolidated to $3.8 \mathrm{MPa}$. It was then heated from $25^{\circ} \mathrm{C}$ to $76^{\circ} \mathrm{C}$ under drained conditions and constant mean effective stress. At $76^{\circ} \mathrm{C}$, a standard drained triaxial shear test under constant confining pressure followed. In TCD-2, the same heating was performed but under the initial mean effective stress of $2.5 \mathrm{MPa}$. The sample was also sheared under constant confining pressure.

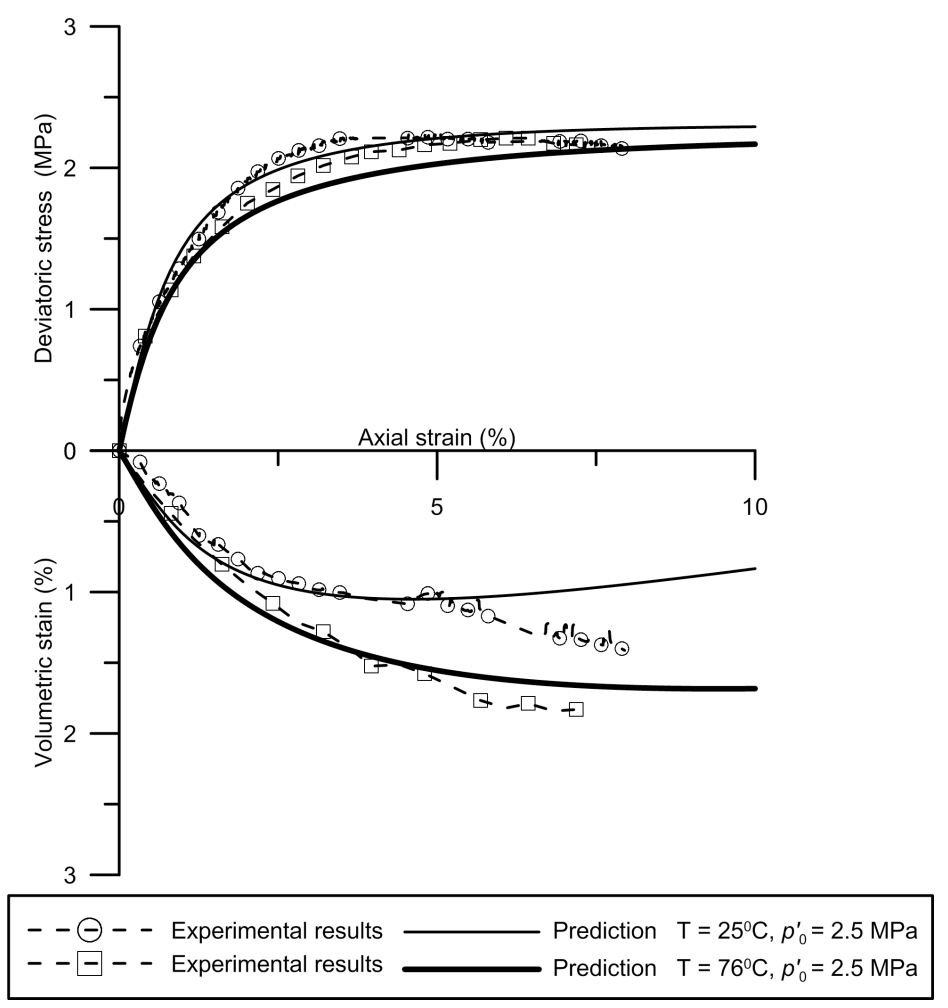

Figure 13. Simulations of the drained triaxial compression tests on natural Boom Clay: CD-1 $\left(T=25^{\circ} \mathrm{C}, p_{0}^{\prime}\right.$ $=2.5 \mathrm{MPa})$ and TCD $-1\left(T=76^{\circ} \mathrm{C}, p_{0}^{\prime}=2.5 \mathrm{MPa}\right)$. 


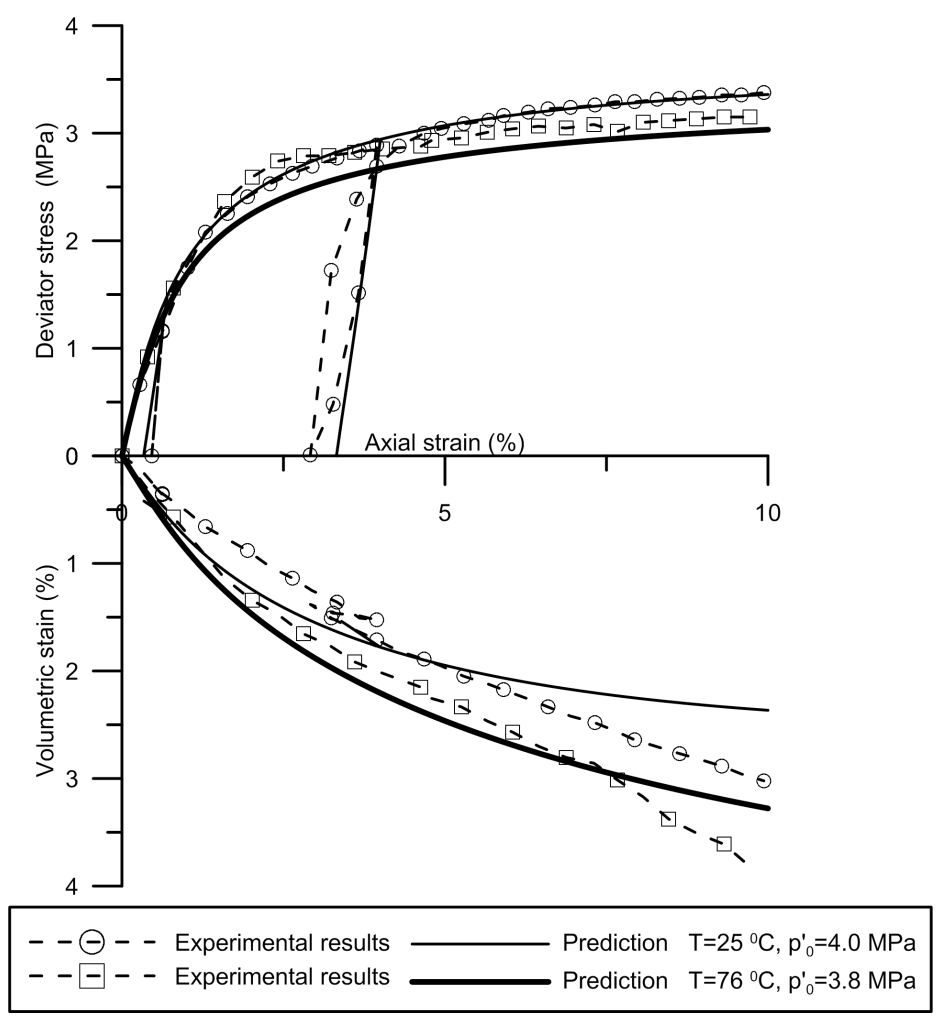

Figure 14. Simulations of the drained triaxial compression tests on natural Boom Clay: CD-2 $\left(T=25^{\circ} \mathrm{C}, p_{0}^{\prime}\right.$ $=4.0 \mathrm{MPa})$ and $\mathrm{TCD}-2\left(T=76^{\circ} \mathrm{C}, p_{0}^{\prime}=3.8 \mathrm{MPa}\right)$.

Using the proposed model, the drained triaxial tests at $25^{\circ} \mathrm{C}$ and $76^{\circ} \mathrm{C}$ at different overconsolidated states were simulated and compared with the experimental results in Figures (13) and (14), respectively. The predicted results in the deviator stress-axial strain plane show a lower conventional yield point in terms of deviator stress at $76^{\circ} \mathrm{C}$, which is consistent with the experimental observations. Moreover, the model also satisfactorily describes the important temperature effects on volume changes: larger volumetric strain is generated at $76^{\circ} \mathrm{C}$ than at $25^{\circ} \mathrm{C}$ as shown in the figures. Furthermore, smooth predictions are obtained in agreement with the experimental results. A slight shear dilatancy is predicted from a large strain $\left(\varepsilon_{1}=5 \%\right)$ in test CD-1 (see Figure 13) due to the adoption of the combined volumetric-deviatoric hardening law, which is not observed experimentally. This difference is to be further examined by other tests.

\section{CONCLUSIONS}

A Two-surface thermo-mechanical model - TEAM model has been developed based on a previous model by Cui et al. [3]. Two plastic mechanisms are introduced: the first- namely TY- allows the thermo-plasticity involving thermal expansion and contraction observed at high over-consolidation ratios to be described while the second - namely LY- allows the temperature effects on the conventional pre-consolidation pressure to be depicted. This model 
links the thermal plastic strain and the mechanical one and thus determines the plastic strain through the change in the size of the yield surface, irrespective of loading paths. A method has been introduced to determine the thermal yield surface TY from the experimental results according to its thermo-mechanical meaning. To describe some important features of the mechanical behavior of natural clays under non-isothermal conditions, general expressions are adopted for the yield and plastic potential in $p^{\prime}-q-T$ plane. To account for the plastic behavior inside the conventional thermo-mechanical yield surface (TY and LY), additional yield surfaces (ITY and ILY) are proposed. Respective hardening laws associated with ITY and ILY are also introduced, enabling the plastic modulus to vary flexibly when the thermomechanical loading paths are inside TY and LY. Moreover, the constitutive equations of the model are formulated using the consistency condition of the yield surfaces, making the stress integration easier in the numerical implementation.

Comparison between the model predictions and the experimental results of reconstituted Pontida Clay and natural Boom Clay shows that the TEAM model is able to capture the overall thermo-mechanical behavior of saturated clays along different thermo-mechanical loading paths, in particular, the reduction of the elastic domain with the increase of temperature and the smooth elasto-plastic transition.

\section{Appendix I. Yield Surface Equations}

As presented in McDowell and Hau [28], by integration of the following equation:

$$
\frac{\frac{\partial f}{\partial p^{\prime}}}{\frac{\partial f}{\partial q}}=\frac{M_{f}^{2}-\eta^{2}}{k_{f} \eta}
$$

the generalized surface can be determined:

$$
\begin{array}{ll}
f \equiv q^{2}+\frac{M_{f}^{2}}{1-k_{f}}\left(\frac{p^{\prime}}{\bar{p}_{c}^{\prime}}\right)^{2 / k_{f}} \bar{p}_{c}^{\prime 2}-\frac{M_{f}^{2} p^{\prime 2}}{1-k_{f}}=0 \quad\left(\text { if } \quad k_{f} \neq 1\right) \\
f \equiv q-M_{f} p^{\prime} \sqrt{2 \ln \left(\bar{p}_{c}^{\prime} / p^{\prime}\right)}=0 \quad\left(\text { if } \quad k_{f}=1\right)
\end{array}
$$

The expression with $k_{\mathrm{f}}=1$ has a different from that in the case of $k_{\mathrm{f}} \neq 1$. However, it is interesting to note that the shape of the equation $\left(k_{\mathrm{f}}=1\right)$ can be approximated by equation $\left(k_{\mathrm{f}}\right.$ $\neq 1)$ by choosing $k_{\mathrm{f}}$ close to 1 .

\section{REFERENCES}


[1] Hueckel T, Baldi G. Thermoplasticity of saturated clays. experimental constitutive study. Journal of geotechnical engineering 1990; 116(12):1778 - 1796.

[2] Baldi G, Hueckel T, Peano A, Pellegrini R. Developments in modelling of thermohydro-geomechanical behaviour of boom clay and clay-based buffer materials. Technical Report, Commission of the European Communities, Nuclear Science and Technology 1991.

[3] Cui YJ, Sultan N, Delage P. A thermomechanical model for saturated clays. Canadian Geotechnical Journal 2000; 37(3):607 - 620.

[4] Sultan N, Delage P, Cui Y. Temperature effects on the volume change behaviour of boom clay. Engineering Geology 2002; 64(2-3):135 - 145.

[5] Cekerevac C, Laloui L. Experimental study of thermal effects on the mechanical behaviour of a clay. International Journal for Numerical and Analytical Methods in Geomechanics 2004; 28(3):209 - 228.

[6] Abuel-Naga H, Bergado D, Bouazza A, Ramana G. Volume change behaviour of saturated clays under drained heating conditions: Experimental results and constitutive modeling. Canadian Geotechnical Journal 2007; 44(8):94 -956.

[7] Hong PY, Pereira JM, Tang AM, Cui YJ. On some advanced thermo-mechanical models for saturated clays. International Journal for Numerical and Analytical Methods in Geomechanics 2013; 37(17):2952-2971.

[8] Hueckel T, Borsetto M. Thermoplasticity of saturated soils and shales. constitutive equations. Journal of geotechnical engineering 1990; 116(12):1765 - 1777.

[9] Graham J, Tanaka N, Crilly T, Alfaro M. Modified cam-clay modelling of temperature effects in clays. Canadian Geotechnical Journal 2001; 38(3):608 - 621.

[10] Robinet JC, Rahbaoui A, Plas F, Lebon P. Constitutive thermomechanical model for saturated clays. Engineering Geology 1996; 41(1-4):145 - 169.

[11] Laloui L, François. Acmeg-t: Soil thermoplasticity model. Journal of Engineering Mechanics 2009; 135:932-944.

[12] Hujeux J. Calcul numérique de problèmes de consolidation élastoplastique. $\mathrm{PhD}$ Thesis, Ecole centrale de Paris 1979.

[13] YAO Y, ZHOU A. Non-isothermal unified hardening model: a thermo-elasto-plastic model for clays. Géotechnique 2013; 63(15):1328-1345.

[14] Lê T. Comportement thermo-hydro-mécanique de l'argile de boom. PhD Thesis, École Nationale des Ponts et Chaussées, France 2008.

[15] Hong PY. Development and explicit integration of a thermo-mechanical model for saturated clays. PhD Thesis, Université Paris-Est, France 2013. 
[16] Sultan N. Etude du comportement thermo-mécanique de l'argile de boom: expériences et modélisation. PhD Thesis, École Nationale des Ponts et Chaussées, France 1997.

[17] Wood D. Experimental inspiration for kinematic hardening soil models. Journal of engineering mechanics 2004; 130:656.

[18] Demars K, Charles R. Soil volume changes induced by temperature cycling. Canadian geotechnical journal 1982; 19(2):188-194.

[19] Baldi G, Hueckel T, Pellegrini R. Thermal volume changes of the mineral-water system in low-porosity clay soils. Canadian geotechnical journal 1988; 25(4):807 - 825.

[20] Hueckel T, Pellegrini R. Modeling of thermal failure of saturated clays. ISMES, 1989.

[21] Hueckel T, Pellegrini R, Del Olmo C. A constitutive study of thermo-elasto-plasticity of deep carbonatic clays. International journal for numerical and analytical methods in geomechanics 1998; 22(7):549-574.

[22] Hueckel T, Francois B, Laloui L. Explaining thermal failure in saturated clays. Geotechnique 2009; 59(3):197 - 212.

[23] Del Olmo C, Fioravante V, Gera F, Hueckel T, Mayor J, Pellegrini R. Thermomechanical properties of deep argillaceous formations. Engineering geology 1996; 41(1):87-102.

[24] Delage P, Le TT, Tang AM, Cui YJ, Li XL. Suction effects in deep boom clay block samples. Géotechnique 2007; 57(1):239-244.

[25] Coll C. Endommagement des roches argileuses et perméabilité induite au voisinage d'ouvrages souterrains. PhD Thesis, Université Joseph-Fourier-Grenoble I, France 2005.

[26] Zytynski M, Randolph M, Nova R, Wroth C. On modelling the unloading-reloading behaviour of soils. International Journal for Numerical and Analytical Methods in Geomechanics 1978; 2(1):87-93.

[27] Houlsby G, Puzrin A. Principles of hyperplasticity: an approach to plasticity theory based on thermodynamic principles. Springer, 2006.

[28] McDowell G, Hau K. A generalised modified cam clay model for clay and sand incorporating kinematic hardening and bounding surface plasticity. Granular Matter 2004; 6(1):11-16.

[29] Yu H. Casm: A unified state parameter model for clay and sand. International journal for numerical and analytical methods in geomechanics 1998; 22(8):621-653.

[30] Hong PY, Pereira JM, Cui YJ, Tang AM. Explicit integration of a thermo-mechanical model for clays. Computers and Geotechnics 2012; 46(0):13 - 25. 
[31] Hueckel T, Pellegrini R. Thermoplastic modeling of undrained failure of saturated clay due to heating. Soils and Foundations 1991; 31(3):1-16.

[32] Cui YJ, Le T, Tang A, Delage P, Li X. Investigating the time-dependent behaviour of boom clay under thermomechanical loading. Geotechnique 2009; 59(4):319 - 329. 